\title{
Huge Sacrococcygeal Teratoma in an Adult Female: A Case Report
}

\author{
Yasutake Uchima*, Naoki Aomatsu, Takuma Okada, Hironari Miyamoto, Gen Tsujio, \\ Shigeaki Kurihara, Toshiki Hirakawa, Takehiko Iwauchi, Junya Morimoto, Kazuhiro Takeuchi
}

Department of Surgery, Fuchu Hospital, Izumi, Osaka, Japan

Email: *y_uchima@seichokai.or.jp

How to cite this paper: Uchima, Y., Aomatsu, N., Okada, T., Miyamoto, H., Tsujio, G., Kurihara, S., Hirakawa, T., Iwauchi, T., Morimoto, J. and Takeuchi, K. (2019) Huge Sacrococcygeal Teratoma in an Adult Female: A Case Report. Journal of Cancer Therapy, 10, 197-202. https://doi.org/10.4236/jct.2019.103016

Received: February 1, 2019

Accepted: February 25, 2019

Published: February 28, 2019

Copyright ( 2019 by author(s) and Scientific Research Publishing Inc. This work is licensed under the Creative Commons Attribution International License (CC BY 4.0).

http://creativecommons.org/licenses/by/4.0/ (c) (i) Open Access

\begin{abstract}
Background: Teratomas are a type of germ cell tumor, which are mostly benign, and dominative in adult females. Sacococcygeal teratomas are usually found in newborns or children, and can be detected prenatally; they are exceedingly rare in adults. We reported a case of a sacrococcygeal teratoma in adult female. Case presentation: A 26-year-old female was diagnosed with a presacral tumor 6 years ago. Pelvic computed tomography (CT) demonstrated a presacral heterogeneous tumor, containing multi-located cystic area and enhanced solid component with calcification. Magnetic resonance imaging (MRI) showed a presacral non-enhanced cystic lesion with solid component, $128 \mathrm{~mm} \times 104 \mathrm{~mm} \times 102 \mathrm{~mm}$, which was suspected of having invaded the rectal wall, fifth sacral vertebra (S5), and coccyx. She underwent abdomino-sacral total excision of tumor with coccygectomy. Histopathological examination revealed a tumor with intricate admixture of ectodermal (epidermis, sebaceous glands and squamous), mesenchymal (cartilage, adipose tissue, blood vessels, nerves and skeletal muscle) and endodermal components (respiratory epithelium and intestinal epithelium) respectively. After 24 months of follow-up the patient was both clinically and radiologically disease free. Conclusions: Early complete excision was the preferred definitive modality of treatment for sacrococcygeal teratoma, and multi-staged excision and reconstruction resulted in successful and safe treatment in our case.
\end{abstract}

\section{Keywords}

Sacrococcygeal Teratoma, Adult, Surgical Treatment

\section{Background}

Teratomas are a type of germ cell tumor, which are mostly benign, and domina- 
tive in adult females [1] [2]. Sacrococcygeal teratoma is the most common congenital neonatal tumor but rarely seen in adults. Prevalence of sacrococcygeal teratoma varies from $1 / 14,900$ to $1 / 40,000$ live births in various series and occurs more often in girls, with female to male ratio of 34:1 [3] [4] [5] [6]. Most of the sacrococcygeal teratomas are cystic and benign and only $12 \%$ are malignant [7]. Teratomas are defined as tumors, which are composed of various elements including the mesoderm, endoderm, and ectoderm. The cystic lumen mainly contains sebaceous materials and hairs. Treatment consists of complete surgical resection and coccygectomy. Prognosis of sacrococcygeal teratoma depends on the extent of surgical resection and histopathological findings of tumor (benign or malignant).

\section{Case Presentation}

A 26-year-old female who presented with anuria was referred to our hospital. Six years at another hospital she was diagnosed as having a presacral tumor tumor on computed tomography (CT). She was followed up for six years without treatment. On admission to our hospital, she was diagnosed as having a presacral tumor on CT (Figure 1). Digital examination showed a palpable hard mass with smooth surface beyond the right-posterior wall of the rectum. Routine laboratory tests were all within normal ranges. The serum alpha fetoprotein (AFP), carcinoembryonic antigen (CEA), lactate dehydrogenase (LDH) and $\beta$ human chorionic gonadotropin ( $\beta$ HCG) levels were also normal. The serum carbohydrate antigen 19-9 (CA19-9) was $87 \mathrm{U} / \mathrm{ml}$ (normal range, <37 U/ml). An enhanced pelvic CT scan demonstrated a presacral heterogeneous tumor, 140 $\mathrm{mm} \times 107 \mathrm{~mm}$, containing a multiloculated cystic area and enhanced solid component with calcification. There was no evidence of distant metastasis. Magnetic resonance imaging (MRI) showed a presacral non-enhanced cystic lesion with solid component, $128 \mathrm{~mm} \times 104 \mathrm{~mm} \times 102 \mathrm{~mm}$, which was suspected

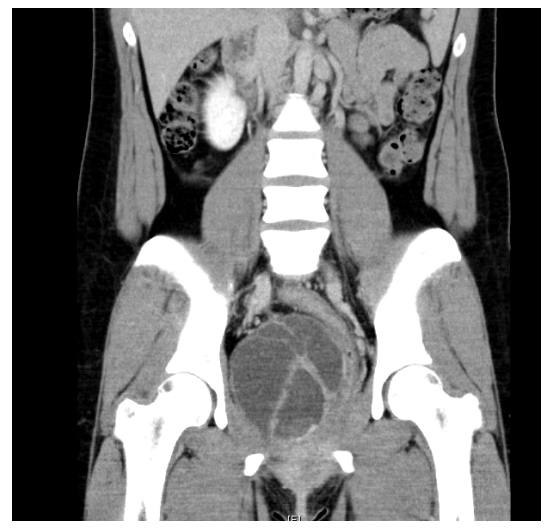

(a)

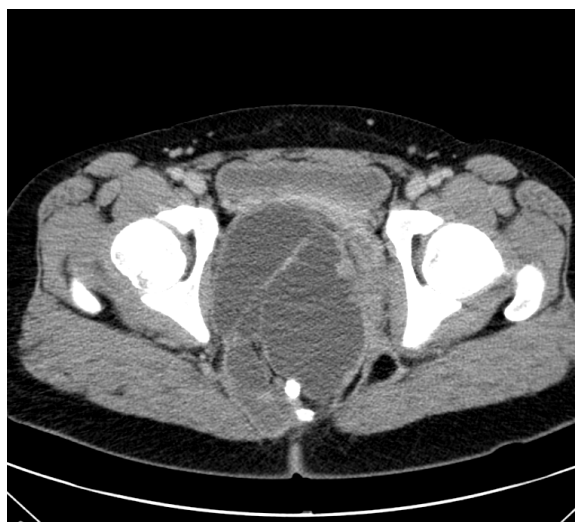

(b)

Figure 1. An enhanced pelvic CT scan demonstrated a presacral heterogeneous tumor, $140 \mathrm{~mm} \times 107 \mathrm{~mm}$, containing a multiloculated cystic area and enhanced solid component with calcification. The tumor was compressing the bladder and the rectum. (a) Coronal plane; (b) Transverse plane. 
of having invaded the rectal wall, fifth sacral vertebra (S5), and coccyx (Figure 2). Based on these findings, the patient was diagnosed as having a sacrococcygeal teratoma with/without malignant transformation into adenocarcinoma.

Intraoperatively, there was a large cystic mass in sacrococcygeal region with extension to the lower third of the rectum and adherent to the coccyx. The rectum was dissected off the presacral fascia and the tumor was dissected along with coccyx.

Patient underwent abdomino-sacral total excision of tumor with coccygectomy. On laparotomy, there was no evidence of liver metastasis or peritoneal dissemination. The tumor was palpable on the right side of the rectum. The rectum was fully mobilized and the periosteum of the upper edge of the coccyx was exposed. The second step was sacral resection. The patient was placed in a jackknife position, a median incision not including the anus was made, and coccyx amputation was carried out using the chisel at the upper edge of coccyx. Following this, the tumor was completely resected from the pelvic floor sparing the rectum (Figure 3).

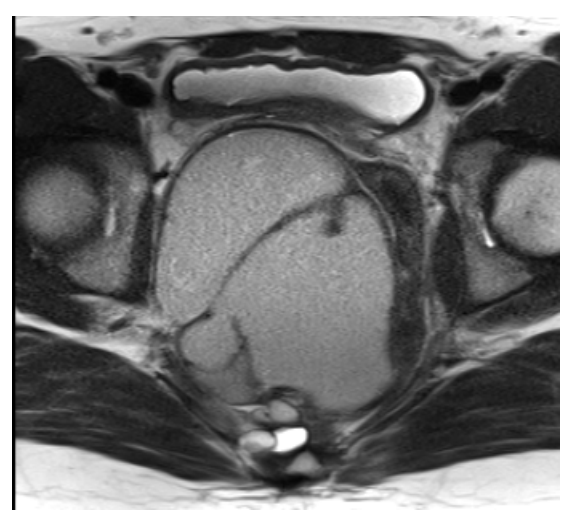

(a)

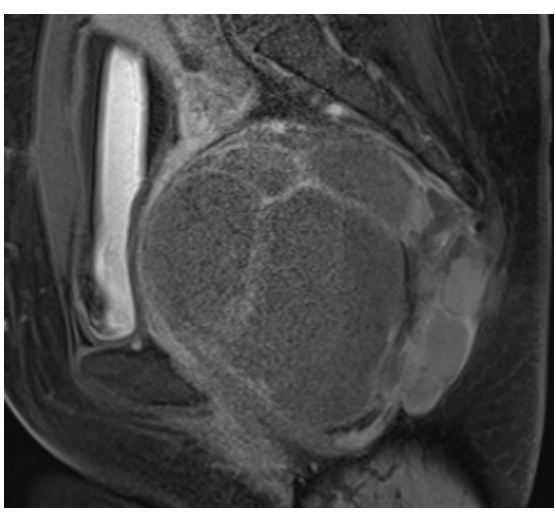

(b)

Figure 2. MRI showed a presacral non-enhanced cystic lesion with solid component, 128 $\mathrm{mm} \times 104 \mathrm{~mm} \times 102 \mathrm{~mm}$, which was suspected of having invaded the rectal wall, fifth sacral vertebra (S5), and coccyx. (a) T1 transverse plane; (b) T2 sagittal plane.

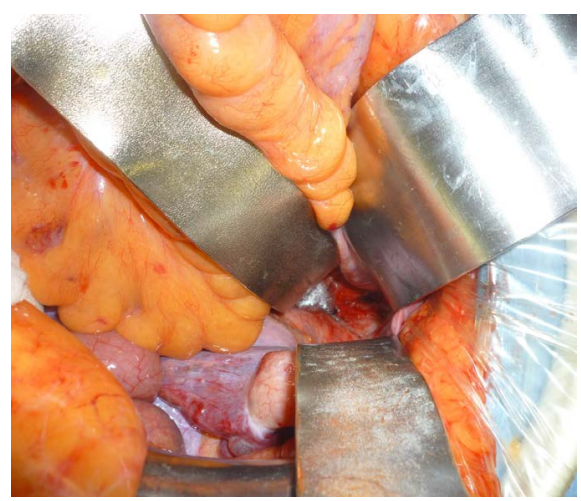

(a)

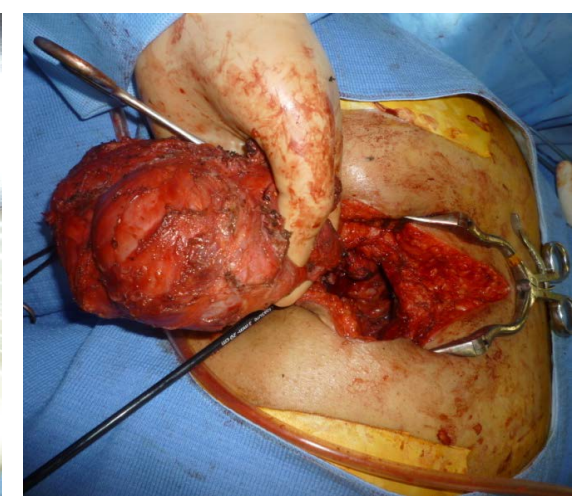

(b)

Figure 3. (a) Intraoperative photographs show that the tumor was palpable on the right side of the rectum; (b) En-bloc resection of the tumor with coccyx. 
Histopathological examination revealed a tumor with intricate admixture of ectodermal (epidermis, sebaceous glands and squamous), mesenchymal (cartilage, adipose tissue, blood vessels, nerves and skeletal muscle) and endodermal components (respiratory epithelium and intestinal epithelium) respectively (Figure 4). A small focus of neuroglial tissue was also seen and no immature components were seen. Overall features were those of mature teratoma (Figure 4).

The patient recovered without showing any post operative complication. She did not have dysuria and defection disorder. In view of mature teratoma without any aggressive features and complete surgical excision patient was kept on regular follow up. At 36 months of follow up patient is both clinically and radiologically disease free.

\section{Discussion}

Teratomas are germ cell tumors commonly composed of multiple cell types derived from one or more of the three germ cell layers. Sacrococcygeal teatomas are rare in adults with only a few published cases in the literature [8] [9] [10] [11] [12]. Most of the adult SCT present as intrapelvic masses, whereas on the contrary in neonates, $90 \%$ of SCT are externally visible. Symptoms may be related to mass effects or bulk of the tumor, such as low back pain, bowel or urinary symptoms, venous engorgement of the lower limbs and lower extremity motor power losses. Calcifications in the coccygeal region in the roentgenogram or an anterior displacement of the rectum in the barium enema are findings suggestive of sacrococcygeal teratoma [10]. Computed tomography and MRI are the most significant tools to characterize the mass, to evaluate the intrapelvic extension and relationship to other structures. Macroscopic examination commonly shows partially cystic lesions [10]. Both of our patients had cystic tumor of varying consistency and size. Microscopic features include the presence of derivatives of more than one germ layer. Sacrococcygeal teratomas are classified into three categories based on their histopathological features: entirely mature adult-type tissue, immature and malignant [11]. Mature teratoma (also referred to as benign teratoma) contains obvious epithelial-lined structures as well as mature cartilage and striated or smooth muscle. Immature teratomas contain

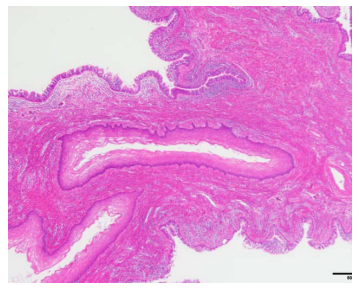

(a)

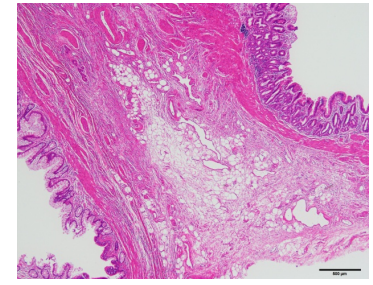

(b)

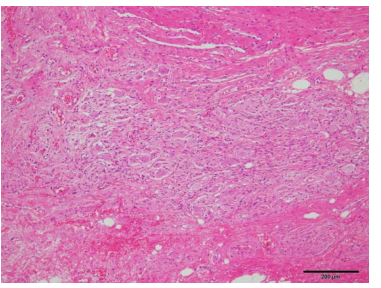

(c)

Figure 4. Microscopic findings (hematoxylin eosin staining) show that a tumor with intricate admixture of ectodermal (epidermis, sebaceous glands and squamous), mesenchymal (cartilage, adipose tissue, blood vessels, nerves and skeletal muscle) and endodermal components (respiratory epithelium and intestinal epithelium) respectively. 
primitive mesoderm, endoderm or ectoderm mixed with more mature elements. Malignant teratomas have frankly malignant tissue of germ cell origin in addition to mature and/or embryonic tissues.

It is generally accepted that the patients with sacrococcygeal teratoma in adult are suitable for surgical treatment because of a malignant potential. Once the malignant transformation aries, only en-bloc radical resection offer the possibility of a good outcome. However, it is often difficult to achieve R0 resection when the tumor has become large and has invaded surrounding organs in the narrow pelvis. Therefore, various surgical approaches have been reported, including tran-abdominal, trans-sacral, and a combined abdomino-sacral approach [13] [14] [15]. In our case, an abdomino-sacral approach was adopted because of the suspicion that the tumor had invaded, not only the rectum but also the distal sacrum and coccyx. The surgical approach selected should be based on various factors including tumor size, location, and invasion to the surrounding organs, and appropriate selection might be the key to successful operation.

If the tumor is histologically benign (mature tissues only) or immature teratoma without frankly malignant tissue, complete excision is adequate. For malignant teratomas, surgical excision alone is inadequate and patients should receive additional treatment with chemotherapy and/or radiotherapy. In view of the rarity of these tumors, there has been no standard recommendation for the use of chemotherapy or radiation.

\section{Conclusion}

Sacrococcygeal teratoma more often occurs in newborns and is only rarely observed in adults, presenting as a gradually enlarging sacrococcygeal cystic mass. Early complete excision is the preferred definitive modality of treatment for sacrococcygeal teratoma, and multi-staged excision and reconstruction result in successful and safe treatment in our case. Mature sacrococcygeal teratoma is rarely malignant in adults, and close follow-up is essential for the detection of early recurrence.

\section{Conflicts of Interest}

The authors declare no conflicts of interest regarding the publication of this paper.

\section{References}

[1] Keslar, P.J., Buck, J.L. and Suarez, E.S. (1994) Germ Cell Tumors of the Sacrococcygeal Region: Radiologic-Pathologic Correlation. Radiographics, 14, 607-620. https://doi.org/10.1148/radiographics.14.3.8066275

[2] Wells, R.G. and Sty, J.R. (1990) Imaging of Sacrococcygeal Germ Cell Tumors. Radiographics, 10, 701-713. https://doi.org/10.1148/radiographics.10.4.2165626

[3] Schropp, K.P., Lobe, T.E., Rao, B., Mutabagani, K., Kay, G.A., Gilchrist, B.F., et al. (1992) Sacrococcygeal Teratoma: The Experience of Four Decades. Journal of Pediatric Surgery, 27, 1075-1078. https://doi.org/10.1016/0022-3468(92)90563-M 
[4] Pauniaho, S.L., Heikinheimo, O., Vettenranta, K., Salonen, J., Stefanovic, V., Ritvanen, A., et al. (2013) High Prevalence of Sacrococcygeal Teratoma in Finland-A Nationwide Population-Based Study. Acta Paediatrica, 102, e251-e256. https://doi.org/10.1111/apa.12211

[5] Golas, M.M., Gunawan, B., Raab, B.W., Füzesi, L. and Lange, B. (2010) Malignant Transformation of an Untreated Congenital Sacrococcygeal Teratoma: An Amplification at $8 \mathrm{q}$ and $12 \mathrm{p}$ Detected by Comparative Genomic Hybridization. Cancer Genetics and Cytogenetics, 197, 95-98.

https://doi.org/10.1016/j.cancergencyto.2009.10.013

[6] Swamy, R., Embleton, N. and Hale, J. (2008) Sacrococcygeal Teratoma over Two Decades: Birth Prevalence, Prenatal Diagnosis and Clinical Outcomes. Prenatal Diagnosis, 28, 1048-1515. https://doi.org/10.1002/pd.2122

[7] Al-Essa, A.A., Malik, T.A., Baghdadi, M.K. and El Tayeb, A.A. (2004) Adult Sacrococcygeal Teratomas. Saudi Medical Journal, 25, 67-69.

[8] Ghosh, J., Eglinton, T., Frizelle, F.A. and Watson, A.J. (2007) Presacral Tumours in Adults. Surgeon, 5, 31-38. https://doi.org/10.1016/S1479-666X(07)80109-0

[9] Audet, I.M., Goldhahn Jr., R.T. and Dent, T.L. (2000) Adult Sacrococcygeal Teratomas. The American Surgeon, 66, 61-65.

[10] Ng, E.W., Porcu, P. and Loehrer Sr., P.J. (1999) Sacrococcygeal teratoma in Adults: Case Reports and a Review of the Literature. Cancer, 86, 1198-1202. https://doi.org/10.1002/(SICI)1097-0142(19991001)86:7<1198::AID-CNCR14>3.0.C $\underline{\mathrm{O} ; 2-\mathrm{M}}$

[11] Luk, S.Y., Tsang, Y.P., Chan, T.S., Lee, T.F. and Leung, K.C. (2011) Sacrococcygeal Teratoma in Adults: Case Report and Literature Review. Hong Kong Medical Journal, 17, 417-420.

[12] Miles, R.M. and Stewart Jr., G.S. (1974) Sacrococcygeal Teratomas in Adult. Annals of Surgery, 179, 676-683. https://doi.org/10.1097/00000658-197405000-00022

[13] Li, G.D., Chen, K., Fu, D., Ma, X.J., Sun, M.X., Sun, W., et al. (2011) Surgical Strategy for Presacral Tumors: Analysis of 33 Cases. Chinese Medical Journal, 124, 4086-4091.

[14] Tulchinksy, H., Tovar, A. and Gutman, H. (2005) Adenocaricnoma within a Paracoccygeal Teatoma in an Adult: Report of a Case. Surgery Today, 35, 259-262. https://doi.org/10.1007/s00595-004-2913-3

[15] Szyllo, K. and Lesnik, N. (2013) Sacrococcygeal Teratoma-Case Report and Review of the Literature. American Journal of Case Reports, 14, 1-5. 